Original Research Paper

\title{
Validation of SSR markers associated with Submergence Tolerance in Rice (Oryza sativa L.)
}

\author{
${ }^{1}$ Kirill V. Azarin, ${ }^{1}$ Alexander V. Usatov, ${ }^{2}$ Andrey V. Alabushev, \\ ${ }^{2}$ Pavel I. Kostylev, ${ }^{1}$ Maxim S. Makarenko and ${ }^{1}$ Aleksey A. Kovalevich

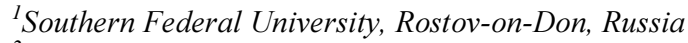 \\ ${ }^{2}$ All-Russian Research Institute of Grain Crops after I.G. Kalinenko, Zernograd, Russia
}

Article history

Received: 23-06-2016

Revised: $15-12-2016$

Accepted: 19-12-2016

Corresponding Author:

Kirill V. Azarin

Southern Federal University,

Rostov-on-Don, Russia

Email: azkir@rambler.ru

\begin{abstract}
The present work is devoted to the validation of SSR markers associated with submergence tolerance $(S u b 1 A)$ QTLs in rice. It was shown that only microsatellite markers RM 7481 differentiates donor lines and recipient variety. Based upon the results of DNA analysis with the marker of the RM 7481 of the $\mathrm{F}_{2}$-plants, the 14 homozygotes by the locus $S u b 1 A, 40$ samples carried SublA in the heterozygous state, 22 plants inherited only alleles from the recipient variety Novator were identified. Survival analysis of parental and hybrid plants (21 days after germination) showed that the most submergence tolerance forms were donor lines of $S u b 1 A$ loci and $F_{2}$-plants carrying $S u b 1 A$ locus in homozygous and heterozygous state according to the data of molecular genetic analysis. Thus, it was shown that RM 7481 microsatellite marker is effective for breeding of submergence tolerance rice using Russian elite cultivars.
\end{abstract}

Keywords: Sub1A, Submergence Tolerance, DNA-Markers, Rice

\section{Introduction}

Development of the submergence tolerant versions of rice cultivars due to the fact that extensive growing areas in South and Southeast Asia are prone flash floods during the monsoon season (Septiningsih et al., 2009; Linh et al., 2013). Another aspect of the use this trait is the transition from seedling to direct sowing seeds. In Russia complete flooding is used to weed control because they can not overcome deep layer of water. Therefore, it is necessary the submergence-tolerant rice cultivars. A considerable stage in the history of breeding for submergence tolerance in rice it was mapped on chromosome 9 the major Submergence 1 (SUB1) QTL (Xu et al., 2006).

As was shown SUB1 QTL carries three related Ethylene Response Factor (ERF)-like genes (Sub1A, B and $C$ ), however, only $S u b 1 A$ was strongly induced in the tolerant varieties in reaction to flooding (Xu et al., 2006; Fukao et al., 2009). In Russia like in several countries cultivated rice belongs to the subspecies japonica, but $S u b 1 A$ is absent from all japonica cultivars. Therefore introgression the $S u b 1 A$ QTL into the elite rice cultivars of Russia by marker-assisted selection is a real an urgent objective.

Nevertheless, association microsatellite locus alleles with specific trait in a certain population do not always correlate with that trait in population other origin (Neeraja et al., 2007; Singh et al., 2010; Usatov et al., 2015; 2016). In this connection, the validation of SSR markers associated with submergence tolerance in rice for to transfer the SublA locus into genotype of the high-yielding Russian variety of rice was conducted.

\section{Materials and Methods}

\section{Plant Materials}

The highly productive Russian variety Novator was used as the recipient. Varieties Inpara-3, BR-11, TDK-1, CR-1009 was used as a donor Sub1A region. For validation of SSR markers associated with submergence tolerance in rice the hybrids by crossing varieties Novator with Sub1A gene donors were obtained. The $\mathrm{F}_{1}$-plants were characterized by a high sterility (90-95\%), indicating a significant genetic difference between the parental forms. Out of the second generation were selected 20 rice plants based on traits of earliness, short stature, plant height, grain content to panicles, non-shattering and spikelets fertility based on for each combination of crossing, respectively. The selected plants were analyzed for the presence of introgression locus. 


\section{Molecular Marker Analysis}

For molecular genetic analysis 7 SSR microsatellite markers flanking the locus $S u b 1 A$ were selected (http://www.gramene.org). Descriptions of the primers are shown in Table 1. Polymorphism between donors and recipient was surveyed using these markers. To perform the molecular genetic analysis, genomic DNA was isolated from leaf tissue as described in (Boom et al., 1990), with our modification (Markin et al., 2015). Polymerase chain reaction was carried out in $25 \mu \mathrm{L}$ reaction mixture of the following composition: $67 \mathrm{~mm}$ Tris- $\mathrm{HCl}$ buffer, pH 8.8, $16 \mathrm{mM}$ (NH4)2SO4, $2.5 \mathrm{mM} \mathrm{MgSO} 4,0.1 \mathrm{mM}$ mercaptoethanol, $0.25 \mathrm{mM}$ of each dNTP (dATP, dCTP, dTTP and dGTP), 20 pM primers, 2.5 units of Taq polymerase and $15 \mathrm{ng}$ isolated DNA (Usatov et al., 2014). Amplification was performed in the thermo cycler Palm Cycler (Corbett Research, Australia). Thermal regime of the reaction was chosen individually for each pair of primers on the basis of their sequences. For majority of reactions the optimal thermal regime was as follows: (1) denaturation at $94^{\circ} \mathrm{C}$ for $3 \mathrm{~min}$, (2) 30 cycles at the following thermal and time regime: Primer annealing at $55-59^{\circ} \mathrm{C}$ for 35 and $30 \mathrm{sec}$ elongation at $72^{\circ} \mathrm{C}$, denaturation at $94^{\circ} \mathrm{C}$, $35 \mathrm{sec}$, (3) $7 \mathrm{~min}$ final elongation at $72^{\circ} \mathrm{C}$ (Usatov et al., 2014). Amplification products were analyzed by electrophoresis in $2 \%$ agarose gel supplemented with ethidium bromide in Tris-Borate buffer. The obtained gels were photographed with the Gel-Documenting system (GelDoc 2000, BioRad, United States). Gene Ruler $1 \mathrm{~Kb}$ DNA Ladder (Fermentas, Lithuania) was used as a molecular weight marker.

\section{Evaluation of Submergence Tolerance}

In a laboratory experiment, rice seeds were soaked in water for $12 \mathrm{~h}$ and then were sown in the soil (Azarin et al., 2016). Deep flooding was simulated in an aquarium with a $50 \mathrm{~cm}$ layer of water (Fig. 1). Control plants were grown in physiological normal conditions. After 21 days the survival rate was measured.

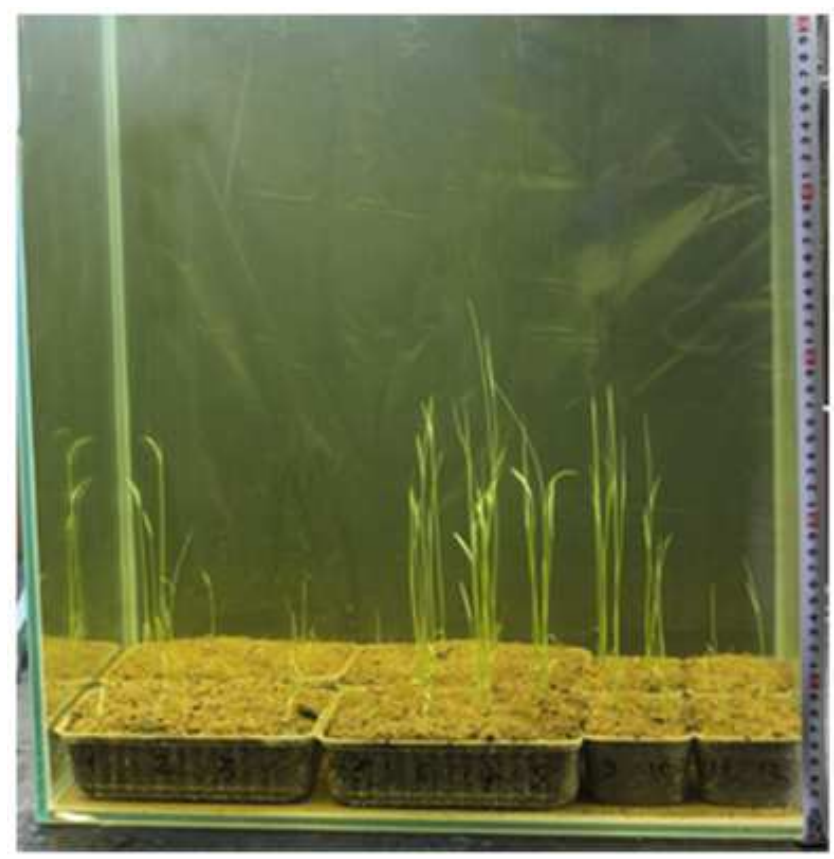

Fig. 1. The evaluation of submergence tolerance

Table 1. SSR markers linked with submergence tolerance locus SublA

\begin{tabular}{lllll}
\hline SSR locus & Forward primer & Reverse primer & Annealing temp $\left({ }^{\circ} \mathrm{C}\right)$ & Product size $(\mathrm{bp})$ \\
\hline RM 219 & cgtcggatgatgtaaagcct & catatcggcattcgcctg & 55 & 202 \\
RM 316 & ctagttgggcatacgatggc & acgcttatatgttacgtcaac & 55 & 210 \\
RM 444 & gctccacctgcttaagcatc & tgaagaccatgttctgcagg & 55 & 139 \\
RM 464 & aacgggcacattctgtcttc & tggaagacctgatcgtttcc & 55 & 262 \\
RM 7481 & cgacccaatatcttctgcc & attggtcgtgctcaacaag & 59 & 95 \\
RM 8303 & aggggagaggacacacacac & ggatcctcctgcaaaatcaa & 59 & 129 \\
RM 23877 & tgccacatgttgagagtgatgc & tacgcaagccatgacaattcg & 59 & 327 \\
\hline
\end{tabular}




\section{Statistical Analysis}

The collected data were subjected to Student's ttest. All data were represented by an average of the three biological replicates and the standard deviations.

\section{Results}

\section{Parental SSR Polymorphism Screening}

In this study, 7 microsatellite markers associated with the Sub1A loci were checked with three donor lines and recipient variety in order to find out polymorphic markers to further use for screening the SublA of the crossing populations. The molecular analysis of parent's varieties by 7 SSR markers of the SublA loci showed that only RM 7481 differentiates donor lines and recipient variety and it is informative for identification of the $S u b 1 A$ region in hybrid population.

In the case of the presence SublA locus in the genome of the test plants the length of amplified fragments according to electrophoregram was about 95 base pairs (Fig. 2). The fragments with the same molecular weight on electrophoregram $(\sim 95 \mathrm{bp})$ were identified for donor lines BR-11, Inpara-3, CR-1009 and TDK-1, while the amplification product of the RM 7481 marker for variety Novator was a distinctive molecular weight ( $\sim 70 \mathrm{bp})$.

\section{Molecular Marker Analysis}

The electrophoretic analysis of PCR products with marker RM 7481 are shown in Fig. 3. The donor allele of parental line CR-1009 was founded in the homozygous state in the samples 2, 3, 5, 9, 13 and 17. The plants no: $2,4,6-8,10,11,16,18$ and 19 were heterozygous by Sub1A locus, i.e., carried both alleles of donor and recurrent parent. Allele inherited from the variety Novator was revealed in other samples. Thus, upon the results of PCR analysis with marker RM 7481 were identified $14 \mathrm{~F}_{2}$-plants homozygotes by the locus SublA, 40 samples carried SublA in the heterozygous state, 22 plants inherited only the allele from the variety Novator.

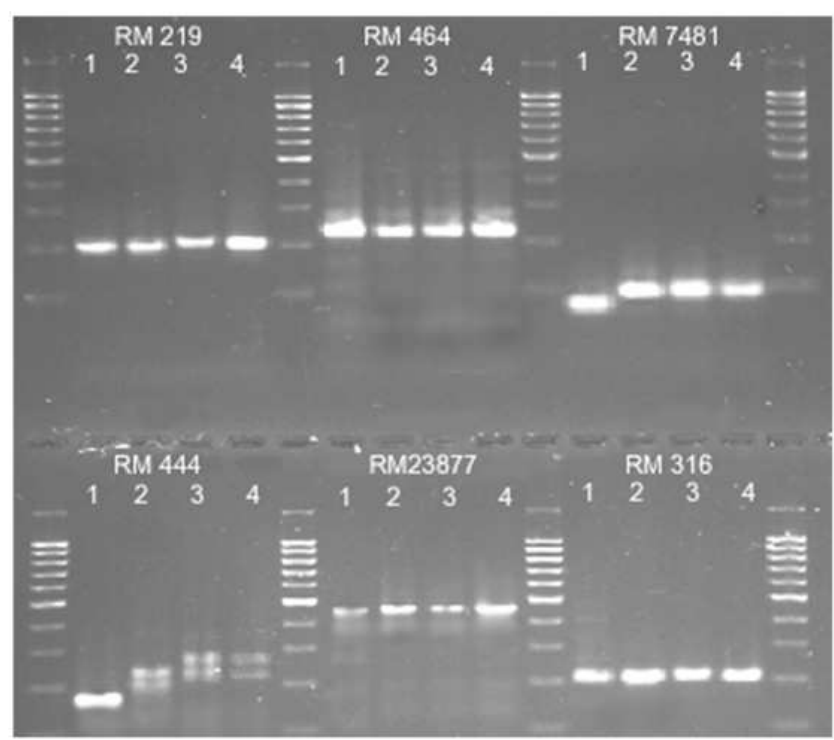

Fig. 2. The electrophoregram of amplification products of genomic DNA of rice. 1- Novator; 2 - BR-11; 3 - CR-1009; 4 - TDK-1. Molecular weight marker-1 Kb

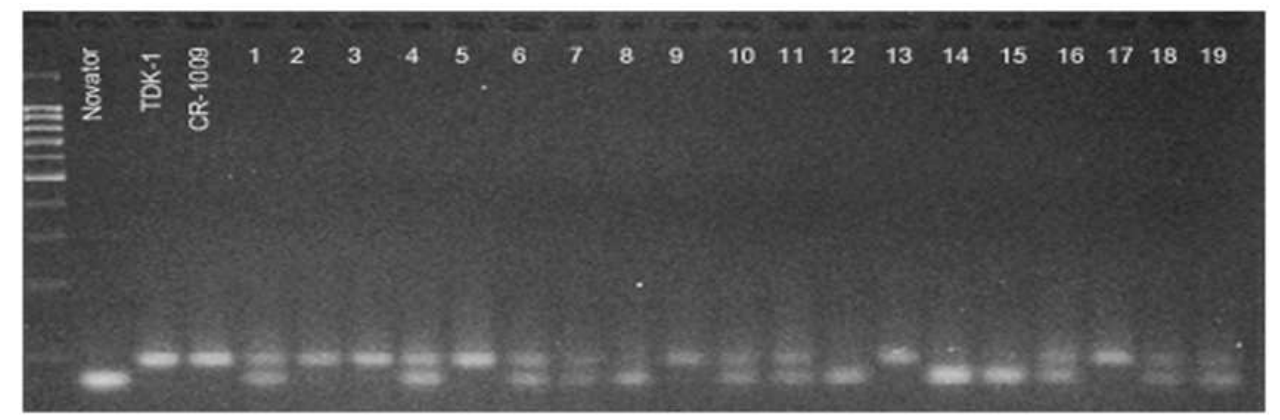

Fig. 3. The electrophoregram of amplification products of genomic DNA of rice with the primer RM 4781. 1-19 - $\mathrm{F}_{2}(\mathrm{CR}-1009 \times$ Novator). Molecular weight marker $-1 \mathrm{~Kb}$ 
Table 2. The survival rates (\%) of rice under control and submergence conditions (21 days after germination)

\begin{tabular}{|c|c|c|c|}
\hline \multirow[t]{2}{*}{ Samples } & & \multicolumn{2}{|c|}{ Survival rate, $(\%)$} \\
\hline & & Control & Submergence \\
\hline Novator & & $98 \pm 1.0$ & $42 \pm 4.0^{*}$ \\
\hline Inpara-3 & & $91 \pm 2.0$ & $87 \pm 2.5$ \\
\hline BR-11 & & $94 \pm 2.5$ & $85 \pm 1.5^{*}$ \\
\hline CR-1009 & & $89 \pm 3.5$ & $85 \pm 3.0$ \\
\hline TDK-1 & & $95 \pm 2.1$ & $89 \pm 4.7$ \\
\hline \multicolumn{4}{|c|}{ Inpara-3 $\times$ Novator } \\
\hline & Homozygotes (SublA) & $91 \pm 2.0$ & $89 \pm 1.5$ \\
\hline & Heterozygotes & $93 \pm 2.0$ & $85 \pm 4.5$ \\
\hline & Homozygotes (without Sub1A) & $91 \pm 1.5$ & $57 \pm 4.0 *$ \\
\hline \multicolumn{4}{|c|}{ BR-11 $\times$ Novator } \\
\hline & Homozygotes $(S u b 1 A)$ & $92 \pm 2.0$ & $85 \pm 3.5$ \\
\hline & Heterozygotes & $94 \pm 1.0$ & $83 \pm 1.1 *$ \\
\hline & Homozygotes (without Sub1A) & $94 \pm 1.5$ & $47 \pm 2.7 *$ \\
\hline \multicolumn{4}{|c|}{ CR-1009 $\times$ Novator } \\
\hline & Homozygotes $($ SublA) & $90 \pm 2.0$ & $87 \pm 2.7$ \\
\hline & Heterozygotes & $90 \pm 1.0$ & $87 \pm 2.5$ \\
\hline & Homozygotes (without SublA) & $91 \pm 1.5$ & $49 \pm 3.0 *$ \\
\hline \multicolumn{4}{|c|}{ TDK-1 $\times$ Novator } \\
\hline & Homozygotes $($ SublA) & $93 \pm 2.0$ & $86 \pm 3.7$ \\
\hline & Heterozygotes & $95 \pm 1.0$ & $87 \pm 4.6$ \\
\hline & Homozygotes (without SublA) & $95 \pm 1.5$ & $45 \pm 2.2 *$ \\
\hline
\end{tabular}

\section{Evaluation of Submergence Tolerance}

For validation of genic-SSR markers it is very important the consistency of the genotyping data and morphophysiological response to the stress. Survival analysis of parental and hybrid plants (21 days after germination) showed that submergence significantly decreased survivability of variety Novator and hybrids without SublA locus. The most submergence tolerance samples at survival rates were donor lines of $S u b 1 A$ loci and hybrids $\mathrm{F}_{2}$ carrying SublA locus in homozygous state (deviation from the control $<15 \%)$. Hybrid plants $\left(\mathrm{F}_{2}\right)$ with locus $\operatorname{SublA}$ in heterozygous state also showed high tolerance to submergence (Table 2).

\section{Discussion}

The peculiarity of flooding as a stress factor for plants is the combination of high water content and oxygen deficit. The access of oxygen to plants roots is hampered by the extremely low oxygen diffusion in water compared to air (Jung et al., 2010; Fukao et al., 2011; Mickelbart et al., 2015). In this case there are inhibited the seed germination, reduced water absorption and inhibited the process of exudation (Kawano et al., 2009; Fukao et al., 2011). The absorption of ions through the roots is dramatically decreased. As a result, it is revealed nutrient deficiencies in shoots, which leads to stunted growth and plant death. Development of oxidative stress is the common response to hypoxia and anoxia in plant tissues (Banti et al., 2013). Even a short period of flooding in the early stages of plant development significantly reduces crop productivity (Kawano et al., 2009; Niroula et al., 2012). However, some plant species tolerate oxygen deficiency in the soil. In this regard rice is a unique crop, which is usually grown in flooded soil. However, not all rice varieties according to its genotype can tolerate to complete flooding. The possibility to grow under submergence condition (hypoxia and anoxia) is provided by the locus $S u b 1 A$, encodes by ethylene-response factor transcription (Xu et al., 2006; Mickelbart et al., 2015). To save energy and carbohydrates in plants carrying $S u b 1 A$ is inhibited the expression of genes encoding a-amylase and sucrose synthase involved in the metabolism of starch and sucrose (Lasanthi-Kudahettige et al., 2007; Banti et al., 2013). Sub1A allows submerged rice plants to save carbohydrates for use after flooding (Banti et al., 2013).

Therefore, the introgression of the SublA locus into the high-yielding varieties using marker-assisted selection will lead to the development of new submergencetolerant lines less time consuming (Linh et al., 2013; Usatov et al., 2015).

In our study, of the seven SSR markers analyzed, only RM 7481 differentiates donor from recipient forms and had a clear codominant inheritance. To validation of the marker RM 7481 the hybrids by crossing Novator 
(elite rice variety of Russia) with $\operatorname{SublA}$ gene donors (lines BR-11, Inpara-3, CR-1009, TDK-1) were obtained. According to the results of molecular genetic screening with RM 7481, the samples carrying different allelic variants Sub1A locus were identified, some of them were homozygous. Investigation of the effect of introduced locus on morpho-physiological characters of rice showed that the most viable samples under submergence were $S u b 1 A$ locus donor lines and hybrid plants $\left(\mathrm{F}_{2}\right)$ carrying the $S u b 1 A$ locus in a homozygous state. The second generation hybrids carrying the $S u b 1 A$ locus in a heterozygous state were also highly tolerance to submergence. Comparative study of agronomic traits of the parental and hybrid plants grown under normal field condition demonstrated that homozygotes by $S u b 1 \mathrm{~A}$ locus have a similar morphotype with the high-yielding cultivar Novator (data not shown). Thus, according to laboratory and field experiments the resulting hybrids have shown a more tolerance to submergence compared to Novator and more adapted to the agro-climatic conditions of rice growing in Russia compared with donor lines.

\section{Conclusion}

The present study aimed at the validation of SSR markers associated with submergence tolerance QTLs Sub1A in rice to introgression of this QTL into the elite rice variety of Russia. It was shown that only RM 7481 differentiates donor lines and recipient variety and it is informative for identification of the $S u b 1 A$ region in hybrid population. To validation of the marker RM 7481 we obtained hybrid combinations of $F_{1}$, then $F_{2}$ between the sensitive and tolerant varieties. It was confirmed, that the mode of inheritance of RM 7481 is codominant. Studying the impact of introduced locus on survival of rice plants under submergence showed that the most tolerant plants were the donor lines of SublA loci and second generation hybrids carrying $S u b 1 A$ in homozygous state according to the data of molecular genetic analysis. Thus, it was shown that RM 7481 microsatellite marker may be effectively utilized for breeding of submergence tolerance rice using Russian elite cultivars.

\section{Funding Information}

This work was supported by the Ministry of Education and Science of the Russian Federation, project no. 40.91.2014/K and Grant of President of Russian Federation no. MK-6123.2016.11.

\section{Author's Contributions}

All the six authors participated in all experiments, data analysis and the entire process of the writing of the manuscript.

\section{Ethics}

The authors declare that this manuscript conforms to the ethical standards specified by the American Journal of Agricultural and Biological Sciences.

\section{References}

Azarin, K.V., A.V. Alabushev, A.V. Usatov, P.I. Kostylev and N.S. Kolokolova et al., 2016. Effects of salt stress on ion balance at vegetative stage in rice (Oryza sativa L.). OnLine J. Biol. Sci., 16: 76-81. DOI: $10.3844 /$ ojbsci.2016.76.81

Banti, V., B. Giuntoli, S. Gonzali, E. Loreti and L. Magneschi et al., 2013. Low oxygen response mechanisms in green organisms. Int. J. Molecular Sci., 14: 4734-4761. DOI: 10.3390/ijms 14034734

Boom, R., C.J. Sol, M.M. Salimans, C.L. Jansen and P.M. Wertheim-van Dillen et al., 1990. Rapid and simple method for purification of nucleic acids. J. Clin. Microbiol., 28: 495-503. PMID: 1691208

Fukao, T., T. Harris and J. Bailey-Serres, 2009. Evolutionary analysis of the Subl gene cluster that confers submergence tolerance to domesticated rice. Ann. Botany, 103: 143-150. DOI: $10.1093 / \mathrm{aob} / \mathrm{mcn} 172$

Fukao, T., El. Yeung and J. Bailey-Serres, 2011. The submergence tolerance regulator subla mediates crosstalk between submergence and drought tolerance in rice. Plant Cell, 23: 412-427.

DOI: $10.1105 /$ tpc. 110.080325

Jung, K.H., Y.S. Seo, H. Walia, P. Cao and T. Fukao et al., 2010. The submergence tolerance regulator subla mediates stress-responsive expression of ap $2 /$ erf transcription factors. Plant Physiol., 152: 1674-1692. DOI: 10.1104/pp.109.152157

Kawano, N., O. Ito and J.I. Sakagami, 2009. Morphological and physiological responses of rice seedlings to complete submergence (flash flooding). Ann. Botany, 103: 161-169. DOI: $10.1093 / \mathrm{aob} / \mathrm{mcn} 171$

Lasanthi-Kudahettige, R., L. Magneschi, E. Loreti, S. Gonzali and F. Licausi et al., 2007. Transcript profiling of the anoxic rice coleoptile. Plant Physiol., 144: 218-231. DOI: 10.1104/pp.106.093997

Linh, T.H., L.H. Linh, D.T.K. Cuc, L.H. Ham and T.D. Khanh, 2013. Improving submergence tolerance of vietnamese rice cultivar by molecular breeding. J. Plant Breed. Genet., 01: 157-168.

Markin, N.V., A.V. Usatov, M.D. Logacheva, K.V. Azarin and O.F. Gorbachenko et al., 2015. Study of chloroplast DNA polymorphism in the sunflower (Helianthus L.). Russian J. Genet., 51: 745-751. DOI: $10.1134 / \mathrm{S} 1022795415060101$

Mickelbart, M.V., P.M. Hasegawa and J. Bailey-Serres, 2015. Genetic mechanisms of abiotic stress tolerance that translate to crop yield stability. Nature Rev. Genet., 16: 237-251. DOI: 10.1038/nrg3901 
Neeraja, C.N., R. Maghirang-Rodriguez, A. Pamplona, S. Heuer and B.C.Y. Collard et al., 2007. A markerassisted backcross approach for developing submergence-tolerant rice cultivars Theoret. Applied Genet., 115: 767-776. DOI: $10.1007 / \mathrm{s} 00122-007-0607-0$

Niroula, R.K., C. Pucciariello, V.T. Ho, G. Novi and T. Fukao et al., 2012. SUB1A-dependent and independent mechanisms are involved in the flooding tolerance of wild rice species. Plant J., 72: 282-293. DOI: 10.1111/j.1365-313X.2012.05078.X

Septiningsih, E.M., A.M. Pamplona, D.L. Sanchez, C.N. Neeraja and G.V. Vergara et al., 2009. Development of submergence-tolerant rice cultivars: The $S u b_{1}$ locus and beyond. Ann. Botany, 103: 151-160. DOI: $10.1093 / \mathrm{aob} / \mathrm{mcn} 206$

Singh, N., T.T.M. Dang, G.V. Vergara, D.M. Pandey and D. Sanchez et al., 2010. Molecular marker survey and expression analyses of the rice submergence-tolerance gene $S U B_{1} A$. Theoret. Applied Genet., 121: 1441-1453.

DOI: $10.1007 / \mathrm{s} 00122-010-1400-\mathrm{z}$
Usatov, A.V., A.I. Klimenko, K.V. Azarin, O.F. Gorbachenko and N.V. Markin et al., 2014. DNAmarkers of sunflower resistance to the downy mildew (Plasmopara halstedii). Am. J. Biochem. Biotechnol., 10: 125-129.

Usatov, A.V., A.V. Alabushev, P.I. Kostylev, K.V. Azarin and M.S. Makarenko et al., 2015. Introgression the SalTol QTL into the elite rice variety of Russia by marker-assisted selection. Am. J. Agric. Biol. Sci., 10: 165-169. DOI: 10.3844/ajabssp.2015.165.169

Usatov, A.V., P.I. Kostylev, K.V. Azarin, N.V. Markin and M.S. Makarenko et al., 2016. Introgression of the rice blast resistance genes $P i 1, P i 2$ and $P i 33$ into Russian rice varieties by marker-assisted selection. Ind. J. Genet. Plant Breed., 76: 18-23. DOI: 10.5958/0975-6906.2016.00003.1

Xu, K., X. Xia, T. Fukao, P. Canlas and R. MaghirangRodriguez et al., 2006. SublA is an ethyleneresponse-factor-like gene that confers submergence tolerance to rice. Nature, 442: 705-708.

DOI: $10.1038 /$ nature 04920 